\title{
Desta Heliso
}

\section{Pistis and the Righteous One}

\section{A Study of Romans 1:17 against the Background of Scripture and Second Temple Jewish Literature}

[Pistis und der Gerechte. Eine Untersuchung von Römer 1,17 vor dem Hintergrund der Bibel und der jüdischen Literatur des zweiten Tempels.]

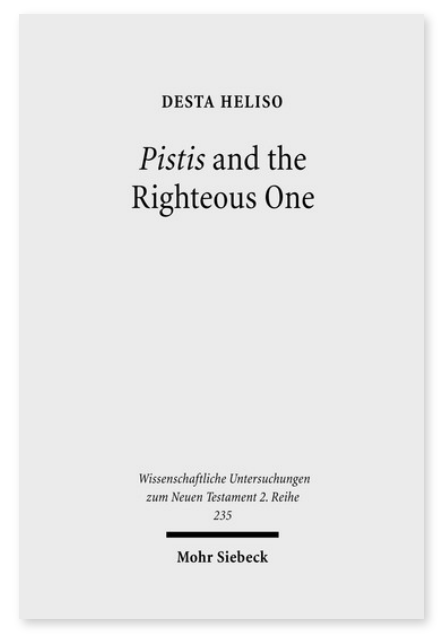

2007. XIV, 292 Seiten. WUNT II 235

ISBN 978-3-16-151578-1

DOI 10.1628/978-3-16-151578-1

eBook PDF 74,00€

ISBN 978-3-16-149511-3

fadengeheftete Broschur 74,00€
Veröffentlicht auf Englisch.

Desta Heliso untersucht Vers 1,17 des Römerbriefes und vergleicht bzw. beurteilt die traditionelle lutherische sowie die christliche Interpretation des Textes. Dabei unternimmt er eine umfassende Exegese der betreffenden Stellen und untersucht die biblischen Hintergründe und die des Zweiten Tempel Judaismus. Im Ergebnis zeigt der Autor schließlich die Schlüssigkeit und Stichhaltigkeit der christlichen Interpretation, während er die Geltung des tratitionell-lutherischen Verständisses des Textes würdigt.

Desta Heliso Born 1964; studied at London School of Theology and Kings' College London, UK; currently lecturer at the Ethiopian Graduate School of Theology in Addis Ababa, Ethiopia.
Jetzt bestellen:

https://mohrsiebeck.com/buch/pistis-and-the-righteous-one-9783161515781?no_cache=1

order@mohrsiebeck.com

Telefon: +49 (0)7071-923-17

Telefax: +49 (0)7071-51104 